\title{
EUDINYR FRAGA
}

EUDINYR FRAGA

é professor de Teatro

Brasileiro na ECA/USP e

autor, entre outros, de
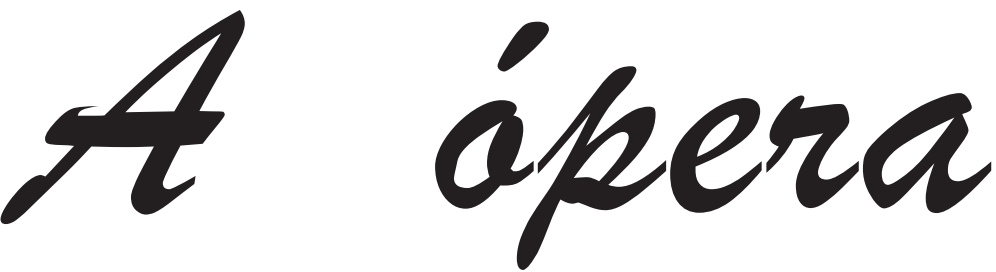

Qorpo-Santo: Surrealismo

ou Absurdo?

A Ópera Alemã, de Lauro

Machado Coelho, São

Paulo, Perspectiva, 2000.
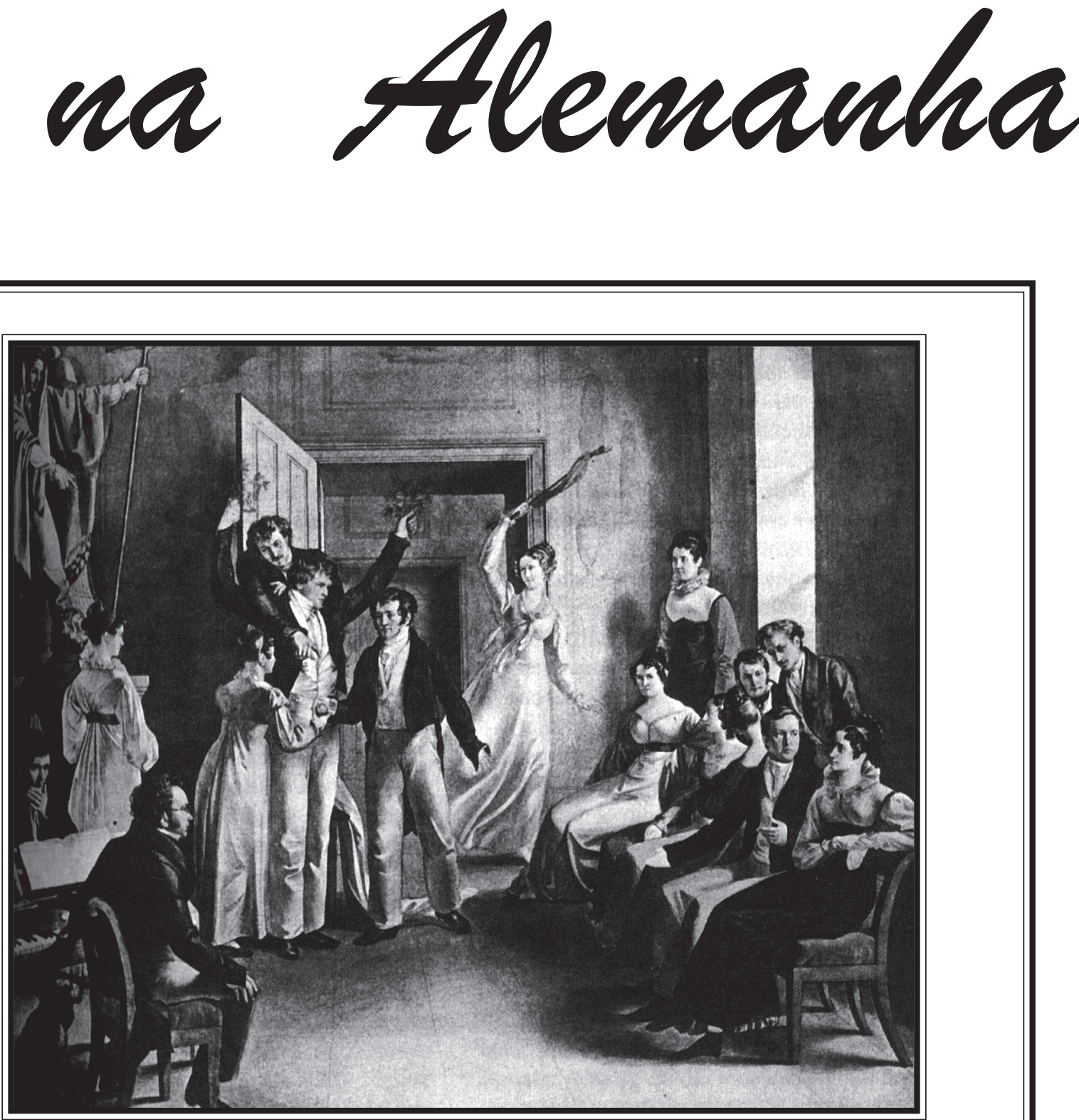

Aquarela de Leopold Kupelwieser, na qual Schubert aparece ao piano 

o sistema tonal, procurando outras alternativas". Ou seja, na futura Ópera Contemporânea serão agrupados e analisados aqueles que procuram abrir outros caminhos para o que se imaginava o impasse da "nova música", na qual se incluía, evidentemente, o gênero operístico, que se envolve com as mais diversas manifestações artísticas, não só no que se refere ao libreto (literatura teatral), mas na sua produção. Otto Maria Carpeaux advertia, em 1958, na sua Uma Nova História da Música, reeditada recentemente, sobre a "crise da música moderna" decorrente "do enjôo dos mundos sonoros antigos". Pelo que concluía seu estudo em 1950, já que boa parte do que se estava produzindo não tinha nada "em comum com aquilo que, a partir do século XIII até 1950, se chamava música", referindo-se, especificamente, à música concreta e eletrônica.

Há uma pontinha de azedume no seu comentário, azedume que já aflorava nas análises de alguns autores e obras, embora declarasse no prefácio que excluíra "na medida do possível preferências e idiossincracias pessoais" (grifo nosso). Mas será que a idiossincracia foi afastada quando denuncia ter Puccini se tornado "fornecedor de melodias para a boîte e para o bar do hotel de luxo"? Ou no leviano julgamento de obras de Tchaikovski: "para muitos, é melhor ter música assim do que música nenhuma", no qual o juízo alheio encobre, na verdade, conivência não disfarçada? Lauro, aliás, com severa simplicidade, qualifica de "ultrapassada" essa obra menor do admirável intelectual austro-brasileiro.

Lauro, ao contrário, conserva sempre essa necessária objetividade, procurando, por exemplo, se não justificar, ao menos compreender a pouca ética (para não dizer oportunismo) de compositores alemães coniventes com o nazismo. Assim, Orff "não

chegou a ser um 'vilão nazista', mas simplesmente acomodou-se às vantagens que a posição de músico respeitado lhe poderia trazer" (comentário da própria filha do compositor). Mas, quanto à alegação de Orff, no final da Segunda Guerra Mundial, de que na Alemanha nazista teria sido fundador de um movimento de resistência denominado "Rosa Branca", Lauro não hesita em fulminar como "invencionice" para salvar a pele. Afinal, infelizmente, não somos Cristo para resistir às tentações de Satã no deserto e nem todos temos estofo de heróis...

Por outro lado, não deixa de investir contra a arrogância e até mesmo a perversidade da família de Richard Wagner, admiradores convictos do führer. Wagner, aliás, é um bom exemplo de como, na história da cultura, a genialidade nem sempre caminha pari passu com a grandeza de caráter. Ou seja, se sua conduta pessoal é passível de crítica, seu comportamento como artista foi irrepreensível, recusando, sempre, qualquer tipo de transigência. Como proceder em relação a tais casos: lamentar o caráter e reconhecer o talento? Talvez o melhor seja parafrasear o fantasma de Hamlet, deixando o julgamento para o céu (leave him to heaven). Objetividade que não o impede de se trair, por vezes, como quando se refere à "típica capacidade de Korngold de escrever melodias que dão um nó na garganta”.

Lauro se move, brilhantemente, entre os diferentes níveis de conhecimento, seja na música, seja nas artes plásticas, seja na literatura, seja no teatro, seja na filosofia, sempre de forma concisa e direta, de modo que o leitor nunca se sente afrontado pela riqueza de informações. Ao contrário, sente-se disposto a ampliá-las e aprofundá-las. Veja-se a abordagem sobre o Romantismo (páginas 161-9), sobre a situação da Alemanha, do final da Primeira Guerra Mundial à eclosão da Segunda, sobre o estilo Biedermeier, sobre Brecht. Quanto ao último, sem desmerecê-lo, não hesita em lamentar sua deplorável adesão ao stalinismo e mesmo sua mensagem "moralmente repulsiva” de Aquele que Diz Sim. 
Sob o título de "ópera alemã" são colocados compositores tanto do mundo germânico propriamente dito, quanto aqueles não-alemães (austríacos, húngaros, tchecos, suíços, italianos) que se abrigaram “sob o amplo guarda-chuva da língua, da cultura, das circunstâncias políticas, da evolução histórica". Lauro, nem por um momento, tem a pretensão de estabelecer um critério sobre o que seria a alma, o espírito germânico. Bem se sabe a precariedade (e infantilidade) de tais generalizações. O que não impede o leitor atento de perceber certas características desse espírito: a tendência à fantasia, a preocupação com sexualidade patológica e situações-limite de desintegração mental e física, que permeiam a dramaturgia e as artes plásticas ligadas ao movimento expressionista, conceito fundamental na abordagem da psique alemã, a atração pelo misterioso, senão mesmo pelo lado mais controvertido da natureza humana, que tanto pode conduzir a uma preocupação místico-religiosa, quanto à intransigência (que não deixa de ser religiosa) da soberbia e do nazismo. Também a predileção pela trama sentimental, a preocupação com o nacionalismo, "a ânsia pelo inalcançável, a contradição permanente entre a necessidade do Absoluto que existe em cada indivíduo e a consciência de que este é um mundo finito, contingente, cuja imperfeição torna impossível a realização ideal de nossos desejos". E, curiosamente, chama a atenção para a tendência dos compositores germânicos pela Gesamtkunstwerk, a obra de arte total, na qual se fundiriam todas as artes, mais tarde sistematizada por Wagner.

O ensaísta ressalva que as obras de Mozart, Wagner e Richard Strauss, fundamentais no desenvolvimento da ópera (não só alemã), receberão tratamento superficial, já que serão abordadas em volumes a elas dedicados. O que não impede a excelência da abordagem, de 32 páginas, sobre a obra do primeiro. Por outro lado, somos surpreendidos sobre a qualidade e a extensão da produção de Siegfried Wagner, filho do genial compositor e que, para nós, brasileiros, é absolutamente desconhecida. E a revalorização de Korngold, mostrando como o relativo ostracismo desse músico é fruto do preconceito nascido dos vanguardistas que viam "em sua riqueza melódica o supra-sumo da velharia", além de ter se dedicado a um gênero "menor", como "música para cinema". Lauro mostra como, ao contrário, o compositor estabeleceu "um padrão de composição 'sinfônica' para a música de cinema que tem, hoje, em sua linhagem, autores como John Williams". O que, em última análise, significa que classificar gêneros como maiores e menores é tolice. Há boa e má música. Aliás a resposta de Korngold sobre a sua resistência ao serialismo é exemplo de honestidade intelectual: "Não se pode espe-
Gravura do século XIX representando uma cena do Fidelio de

\section{Beethoven}

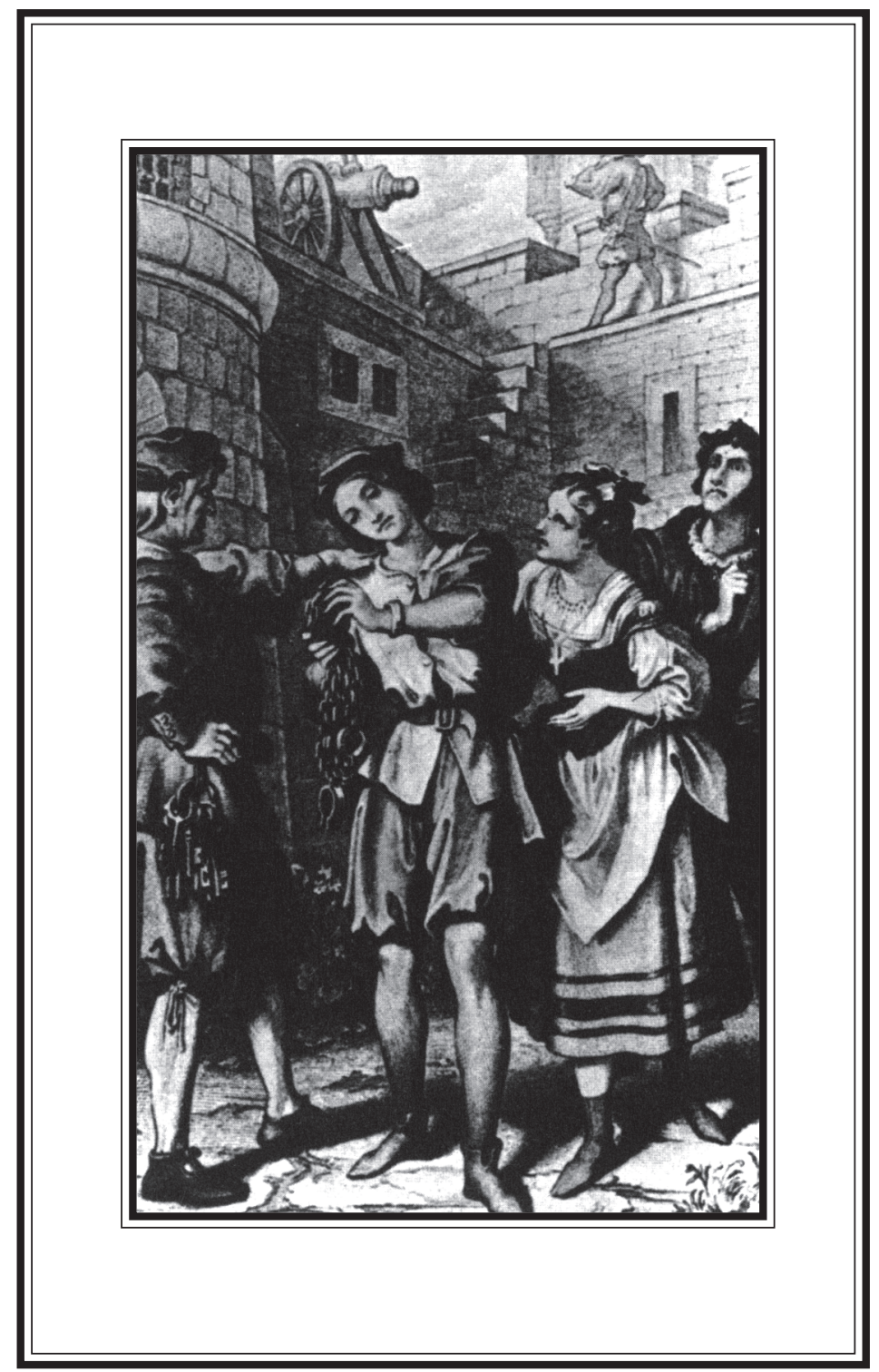


rar que uma macieira dê damascos".

É preciso ressaltar a lúcida abordagem sobre os movimentos radicais da vanguarda dodecafônica, da música serial e pósserial, cuja ortodoxia se opunha a qualquer forma musical que a ela se opusesse. Atitude que conduziu a um comportamento elitista, cavando um fosso entre a música popular e a erudita, “em termos que seriam impensáveis nos tempos de Haendel ou até mesmo de Verdi”. Impossível não lembrar o comentário malicioso de um músico profissional que declarava ter a certeza de que os admiradores incondicionais de tais experiências vanguardistas deviam, às vezes, se encerrar em suas casas, em cômodos totalmente privados, à prova de som, para se deliciar, obscenamente, com algumas deliciosas e palatáveis melodias tonais... Aliás, o ensaísta comenta sobre o paradoxo criado pela intransigência dessa vanguarda que "conduziu a ópera a caminhos muito mais ecléticos: o neotonalismo está em vias de resgatar muitas formas e procedimentos antes considerados obsoletos". O que na prática significa que, brevemente, a vanguarda radical poderá ouvir, com tranqüilidade (e prazer, claro), Catalani e Ponchielli na sala de estar.

Infelizmente, não há como não repetir a eterna queixa sobre a triste situação das nossas montagens operísticas. Todo esse fascinante universo que desfila pelas suas páginas está, infelizmente, proibido para o público brasileiro. Os vídeos e CDs não interessam às distribuidoras ("não há público") e quanto às montagens, então, nem pensar. Além do que, se é enorme prazer escutar ópera, é impossível não se sentir frustrado pela ausência da presença viva, corporal, dos intérpretes, daquela conivência misteriosa que se estabelece entre o palco e a platéia. Cantor de ópera quer palco, disse uma vez a nossa cantora lírica Celine Imbert. E tem razão. Lucia, Carmen, O Barbeiro de Sevilha, Traviata, Tosca, Boheme (partituras, sem dúvida, maravilhosas), estão sempre em eterno rodízio. Mesmo grupos que se dizem experimentais não se dispõem a privilegiar óperas que não exigiriam vozes excepcionais, produções custosas ou orquestras enormes. Veja-se o comentário de Lauro sobre óperas de produção acessível, tais como Sancta Susanna (que poderia ter um atrativo de escândalo para um público pequeno-burguês), Assassino, Esperança das Mulheres, A Longa Noite de Natal, de Hindemith, Uma Tragédia Florentina, de Zemlinski, O Julgamento de Lúculo, de Dessau. E por que não A Cidade Morta, de Korngold, Os Estigmatizados, de Schreker, A Visita da Velha Senhora e A Morte de Danton, de Von Einem? Seriam óperas que poderiam criar um novo e interessado público que olha depreciativamente (e ignorantemente) para aquelas dirigidas a um mesmo e acomodado público. Por falar em Büchner (dramaturgo que escreveu Danton), há uma informação curiosa: ele teria traduzido Maria Tudor, de Victor Hugo. Nada parece mais distante do universo do genial dramaturgo alemão do que o drama romântico francês!

O volume - louve-se novamente a iniciativa pioneira da Editora Perspectiva está muito bem apresentado, com excelente material iconográfico. Pena a ausência de índice remissivo, tão necessário a obra de tal tipo. Há ligeiros deslizes de digitação, no que se refere a datas, facilmente sanáveis. Um reparo: à página 455 Lauro declara que "os diálogos (stichomythia) são em geral salmodiados" (refere-se a Orff). A esticomitia é forma de diálogo que se caracteriza por "troca verbal muito rápida entre duas personagens", um "duelo verbal", nascido já no teatro grego do século V a.C. (Patrice Pavis, Dicionário de Teatro, São Paulo, Perspectiva, 1999).

Como os anteriores, A Ópera Alemã é leitura obrigatória, não só para os que amam música, como para qualquer leitor, já que o obriga a reavaliar conceitos, não somente estéticos mas também éticos, que ultrapassam, e muito, seu objetivo primordial: o desenvolvimento do fenômeno operístico. Inclusive, é obra que deveria ser traduzida e lançada no exterior, pela qualidade e profundidade da pesquisa. 